\title{
Brasil, 2015: como a presidenta, seu partido, seus eleitores e seu governo podem ser conceptualizados em rede social
}

\author{
Ariadne Domingues Almeida*
}

\begin{abstract}
Resumo
São apresentados resultados de um estudo realizado sobre o modo como a presidenta Dilma Rousseff, seu partido, seus eleitores e seu governo foram conceptualizados em um meme postado na página Movimento Contra Corrupção constante da rede social online Facebook. O estudo foi norteado pelos aportes teórico-metodológicos da Linguística Cognitiva. Como a conceptualização é um fenômeno complexo, foram associados conhecimentos adquiridos pela Linguística Cognitiva a saberes elaborados pela Teoria da Complexidade. Foram desenvolvidas reflexões sobre mapeamentos metafóricos e metonímicos, estruturados por esquemas imagéticos no âmbito dessa conceptualização. Ao final dos trabalhos, foi verificado o papel da interconexão entre o imagético e o verbal na geração de sentido, bem como foi observado que, na multimodalidade, o todo é mais do que a soma de suas partes, assim como o todo é menos do que a soma de suas partes.
\end{abstract}

Palavras-chave: Conceptualização. Linguística Cognitiva. Teoria da Complexidade. Multimodalidade. Meme.

\section{PARA INICIAR A TESSITURA TEXTUAL}

O texto ora principiado objetiva, principalmente, promover uma discussão acerca do modo como ocorre a conceptualização da presidenta Dilma Rousseff, do seu partido, dos seus eleitores e do seu governo em um multimodal, especificamente, em um meme. Para subsidiar as discussões apresentadas, guieime por pressupostos da Linguística Cognitiva (doravante, LC), em particular, da Semântica Cognitiva (doravante, SC) e da sua Teoria da Metáfora Conceptual (doravante, TMC), de modo que procurei dialogar com pesquisadores, a exemplo de Forceville (1996, 2007, 2009), bem como busquei contributos da Teoria da

* Universidade Federal da Bahia (ILUFBA-DLV-PPGLinC). 
Complexidade (doravante, TC), trazendo para o debate proposto o pensamento de autores como Capra e Luisi (2014), entre outros. Enfim, para atingir o objetivo primaz deste texto, dividi-o em cinco seções, nas quais foram tecidas as linhas condutoras do meu pensamento ao desenvolver a questão proposta e que culminarão nos resultados, ao final, expostos.

\section{REDES SOCIAIS: ESPAÇOS DE INTERAÇÃO}

No dia a dia de comunidades informatizadas, pessoas interagem com outras, por meio de plataformas digitais ou de softwares sociais, geralmente, chamados de redes sociais online ${ }^{1}$ no caso específico de uma rede de natureza virtual, há um grupo de pessoas que está em interação, através de um meio de mídia de comunicação que pode ser compreendida

como um serviço Web que permite a um indivíduo (1) construir perfis públicos ou semipúblicos dentro de um sistema, (2) articular uma lista de outros usuários com os quais ele(a) compartilha conexões e (3) visualizar e percorrer suas listas de conexões assim como outras listas criadas por outros usuários do sistema. (BENEVENUTO; ALMEIDA; SILVA, 2011).

Entre os variados tipos de rede social online, a Facebook é bem conhecida, tendo uma aderência significativa, em diferentes pontos do planeta, por parte de pessoas com características heterogêneas; essa rede possui, tão somente, doze anos, tendo ocorrido a sua criação, em 2004, nos Estados Unidos, sendo Mark Zuckerberg seu mentor e fundador, com a colaboração de Dustin de Moskovitz, de Chris Hughes e de Eduardo Saverin. Em seus poucos anos de existência, a empresa expandiu-se, ampliou os seus limites, saindo dos muros da Universidade de Harvard, onde foi criada, alcançando, a partir de então, usuários em diversos outros países, para além dos Estados Unidos.

A utilização de redes online tem tido impacto social relevante, em diferentes espaços do globo, de tal sorte que esse uso recorrente tem gerado um empoderamento inconteste para cidadãos, até mesmo para aqueles habitantes de longínquos cantos

1 Embora o uso sintagma redes sociais tenha se tornado, nas comunidades informatizadas, bem usual, no âmbito dos estudos sobre redes sociais, geralmente, é usado junto ao qualificador online, uma vez que nem toda rede social é online; uma rede social caracteriza-se por ser uma estrutura social constituída por pessoas e/ou por organizações que se conectam por diferentes relações e têm valores e metas comuns entre si. 
do planeta, uma vez que as pessoas foram compreendendo que se achavam diante de uma ferramenta poderosa de agrupamento, inclusivamente, até certo ponto, livre de vigilâncias mais apuradas pelos agentes de certas instâncias de poder. Dessa maneira, perceberam que seria possível interagir no plano da virtualidade e, se desejassem, poderiam passar desse plano para os espaços físicos em que teriam experiências e outros contatos para além dos garantidos pelo plano virtual.

A força dessas redes online tem sido estudada por Castells (2013), que discute o papel de protagonista que desempenharam, por exemplo, em manifestações que aconteceram entre 2011 e 2013, em variados espaços sociais, como a Espanha, de modo que ele oferece, ao seu potencial leitor, uma discussão sobre a vitalidade e o empoderamento promovidos por essas redes, que possibilitaram a geração de redes de ruas, de tal modo que a interconexão entre virtual e físico empoderou pessoas para que se fizessem ouvir por quem detém poder.

As redes sociais online, porém, possuem características ambíguas, duais, pois apresentam um tipo de antagonismo, já que se, por um lado, proporcionam o empoderamento humano, por outro, no espaço ântropo-psico-geo-sócio-históricocultural em que são utilizadas, geram uma espécie de isolamento humano, conforme pontuado por Bauman (2007); inserem-se, inclusive, as redes na ecologia da atualidade, que é líquida e fluída, o que tem consequência no modo como ocorre a conceptualização nas sociedades partícipes da cultura virtual.

\section{A CONCEPTUALIZAÇÃO NA SEMÂNTICA COGNITIVA}

Pontuada a importância das redes sociais online, espaço do qual coletei o meme objeto de minhas reflexões, passo a tecer algumas linhas concernentes ao aparato teórico que subsidiou o estudo desse mesmo meme. Assim, trago para o texto a SC, logo, a LC. Considerando esse aparato teórico, compreendo a metáfora, a metonímia e outras figuras como elementos constituintes de operações cognitivas geradoras de significados, as quais regem, cotidianamente, as atividades humanas e se refletem no uso das diferentes linguagens da espécie; assim sendo, essas figuras do pensamento não são vistas, na SC, como fenômenos, simplesmente, linguísticos ou como figuras estilísticas do discurso, uma vez que, para essa área do saber hominal, fica postulado que a linguagem orienta elaboração do significado, ao invés de carregá-lo, como indicou Fauconnier (1994). É posto(a), então, em destaque o(a) conceptualizador(a), o(a) qual, em interação, com a sua mente 
corporificada e com o mundo que o circunda, procederá às diferentes elaborações de sentidos desse e nesse mesmo mundo. O sentido não está, portanto, no texto verbal, ou imagético, ou multimodal, já que a linguagem funcionará como um tipo de bússola que guiará os conceptualizadores em suas elaborações de sentido, que se acham situadas e elaboradas nas interações sociocognitivas da humanidade.

Em síntese, as ditas figuras de linguagem passaram a ser vistas, em SC e, portanto, em LC, como figuras do pensamento com valor cognitivo, funcionando como mecanismos com os quais a espécie humana compreende e constrói o mundo, ou, mais precisamente, ainda, essas figuras passaram a ser vistas como elementos com os quais o ser humano conceptualiza o mundo que o rodeia e com o qual interage e onde acontece a interação com outros seres de sua espécie, com outros viventes e com tudo mais que a humanidade percebe e conceptualiza. Logo, a metáfora, a metonímia e outros mecanismos utilizados pelos humanos na elaboração do sentido, como os esquemas imagéticos, tornaram-se objetos de estudos fundamentais para quem visa a entender como a humanidade erige o mundo, como é capaz de gerar e de compreender a significação, em consequência, como é capaz de agir no mundo.

\subsection{Multimodalidade e conceptualização}

Variados modos semióticos são interconectados pelo(a) conceptualizador(a), em sua elaboração e em sua compreensão dos mais diversos textos multimodais, logo, o sentido é gerado pelas diferentes pessoas conceptualizadoras que promovem a interação desses distintos modos semióticos, já que os multimodais são constituídos pela interconexão de semioses diversas. É, por conseguinte, multimodal qualquer texto em que o(a) conceptualizador(a) utiliza mais de um modo semiótico, em sua elaboração, e os interconecta para a sua compreensão, de tal modo que, por exemplo, o modo visual não é entendido como algo dependente do verbal; assim sendo, inspirando-me na TC, entendo que esses modos semióticos, nos multimodais, possuem padrão de organização e estrutura interconectados por processo. $^{2}$

2 Os conceitos de padrão de organização, estrutura e processo, no âmbito da TC, serão discutidos na próxima seção deste texto, a qual se intitula $A$ Teoria da Complexidade e seus aportes ao estudo da conceptualização multimodal. 
Ainda, norteando-me pelo pensamento de teóricos sistêmicos como Morin (2009), entendo que distintos modos não devem ser decompostos para serem analisados. Isso significa que abandono a perspectiva cartesiana da análise, que decompõe as partes de um todo e, assumindo um posicionamento contrário em relação a tal perspectiva, uso pressupostos da TC, de tal maneira que compreendo ser um texto multimodal um todo que é tecido junto, em que a parte é, ao mesmo tempo, maior e menor do que o todo, de sorte que só pode ser entendido por meio de um olhar holístico (MORIN, 2009). Logo, penso que o modo imagético não é um assessório do escrito. E mais, acredito que

estruturas visuais não simplesmente reproduzem as estruturas da 'realidade'. Pelo contrário, elas produzem imagens da realidade que estão conectadas aos interesses das instituições sociais dentro das quais as imagens são produzidas e lidas. Elas são ideológicas. Estruturas visuais nunca são meramente formais: elas possuem uma dimensão semântica extremamente importante (KRESS; VAN LEEUWEN, 2006, p. 37).

Situada, brevemente, a minha compreensão da multimodalidade, passo a ponderar sobre a realização de estudos a respeito da conceptualização multimodal no âmbito da LC.

Parte considerável das pesquisas ainda se voltam, basicamente, para as metáforas conceptuais monomodais, ou seja, as metáforas em que o domíniofonte e o domínio-alvo ocorrem em um modo semiótico e, em particular, o escrito, deixando de lado outros elementos envolvidos no fenômeno da conceptualização, pois, mesmo que a LC preconize que a metáfora não se limita à linguagem verbal e que, também, as outras figuras do pensamento não ficam restritas ao verbal, a maior parte das investigações sobre esses fenômenos, com base em pressupostos da LC, como ressaltou Forceville (2007), são desenvolvidas a partir de textos monomodais, sendo, quase exclusivamente, verbais.

Embora se realizem pesquisas na seara da multimodalidade, poucas são, ainda, as investidas como os trabalhos de Forceville (1996), ou de Coimbra (2000), ou de Ruiz (2006). Mas, também, é certo, como pontua Schröder (2013, p. 63), que "durante os últimos vinte anos, surgiram cada vez mais abordagens cognitivas que buscam localizar a metáfora conceptual no seu uso multimodal [...]", o que, no entanto, não diminui a emergência de se realizarem pesquisas que tenham a conceptualização multimodal em seu escopo, inclusive, pensando outros elementos para além do seu mecanismo metafórico. 
Como aqui objetivo compreender elementos da conceptualização multimodal, e como a metáfora é, apenas, um dos mecanismos dessa conceptualização, pretendo delinear uma linha de pensamento, observando pressupostos da LC e, também, da TC, a fim de buscar entender parte da organização do processo de conceptualização multimodal, sem seccionar, de um lado, metáfora, de outro, metonímia e de outro, ainda, esquemas imagéticos etc.; assim sendo, todos esses elementos aparecem, no estudo, de forma a colaborarem para a compreensão da conceptualização colocada em pauta, o que faço assumindo os desafios da complexidade.

Sobre a problemática de estudar a multimodalidade, Kress, em 2013, inclusive, já ponderava que a mudança trazida pelas novas formas de comunicação não seria o maior problema que os pesquisadores precisariam enfrentar, mas antes seria o desafio atinente à compreensão desse novo mundo com teorias criadas para tratar de um mundo de estabilidade. Daí, penso ser a união da LC com a TC frutífera para se compreender um mundo de instabilidade estável que caracteriza a linguagem humana em sua poliface. Afinal como assegura Morin (2009, p. 13),

HÁ INADEQUAÇÃO cada vez mais ampla, profunda e grave entre os saberes separados, fragmentados, compartimentados entre disciplinas, e, por outro lado, realidades ou problemas cada vez mais polidisciplinares, transversais, multidimensionais, transnacionais, globais, planetários [...].

Se os saberes tendiam a ser separados, a LC assume o compromisso interdisciplinar, e a TC, além desse compromisso, toma para si o desafio de ir ao encontro das incertezas, tendo ambas a finalidade de vencerem as barreiras da hiperespecialização e de elaborarem conhecimentos antes inatingíveis sobre o fenômeno estudado, aqui, a conceptualização multimodal, que, mesmo sem ser um fenômeno novo na história da humanidade, apresenta, hoje, outras novas facetas advindas da revolução tecnológica.

\subsubsection{Mecanismos da conceptualização multimodal}

No seio da LC, Forceville (2009) compreende o modo como um sistema de signos interpretáveis por processo de percepção específica. Conforme esse autor, esses modos estão, necessariamente, relacionados aos cinco sentidos humanos, havendo, então, os modos pictorial ou visual, sonoro, olfativo, gustativo e tátil. 
E, assumindo a dificuldade de elaborar uma lista de modos, postula a existência de nove tipos modais, incluindo o pictórico, o escrito, o falado, os gestos, os sons, a música, o cheiro, o gosto e o toque.

No plano da multimodalidade, os trabalhos sobre a metáfora possuem maior fôlego, se comparados a estudos que enfocam outros mecanismos de conceptualização. Relativamente aos estudos sobre a metáfora em multimodais, autores, como o próprio Forceville (2009), buscaram subsídios na TMC para desenvolverem suas pesquisas a respeito desse fenômeno e, buscando compreendêlo, acabaram por contrabalançar a atenção dispensada, por mais de três décadas, quase que exclusivamente, às manifestações verbais das metáforas.

Em seus escritos, Forceville (2009) distingue as metáforas monomodais das multimodais. As primeiras caracterizam-se pelo fato de os domínios fonte e alvo encontrarem-se na mesma modalidade, enquanto as outras particularizam-se pelo fato de o domínio-fonte e o domínio-alvo se acharem, exclusiva ou predominantemente, em distintas modalidades.

Em relação à metonímia em perspectiva multimodal, os autores que se dedicam ao seu estudo estão, sempre, ponderando a inexistência de uma discussão mais apurada a seu respeito. E por ser assim, Paiva (2010, p. 7) ressalta a falta de estudos relativos ao fenômeno metonímico, de modo a assegurar que,

apesar de um crescente interesse sobre a metonímia (PANTHER e RADDEN, 1999; BARCELONA, 2003; DIRVEN e PÖRINGS, 2003), a metáfora continua sendo o assunto predileto dos estudiosos sobre produção de sentido como constatam Bredin (1984) e Barcelona (2003a e 2003b), dentre outros.

Com o desenvolvimento de estudos sobre a metonímia na multimodalidade, ficou constatado que as imagens podem funcionar como ponto de referência para, cognitivamente, ativarem outra imagem ou manifestação linguística. Penso, baseando-me em Radden e Kövecses (2007), que a metonímia multimodal é aquela em que, em um mesmo MCI, veículo e meta são ativados por diferentes modos, enquanto, na metonímia monomodal, ambos seriam acionados por um mesmo modo. Logo, na multimodalidade, diferente da monomodalidade, a entidade conceptual, o veículo, promove acesso mental a outra entidade conceptual, o alvo, em um mesmo Modelo Cognitivo Idealizado (doravante, MCI), através de modos distintos. 
Se pouco foi explicitado sobre a relação entre metonímia e multimodalidade, menos ainda foi discutido a propósito das interconexões entre esquemas imagéticose multimodalidade, ainda que, inegavelmente, esses participem da conceptualização multimodal. Creio que os esquemas imagéticos possuam a função de estruturar os mapeamentos metonímicos e metafóricos, na conceptualização multimodal. Diante do exposto, posso afirmar que, ainda, não se aborda, de maneira satisfatória, na conceptualização multimodal, o comportamento dos MCIs - entendidos como mecanismos usados pela espécie humana para compreender o mundo e para gerar conhecimento.

No tocante a essa conceptualização, creio que seja, ademais, necessário ratificar o posicionamento de Forceville (2009), para quem os textos não verbais têm valor basilar para a TMC, uma vez que possibilitam compreender que a metáfora, mas não apenas esta, uma vez que o mesmo é válido para a metonímia, é, de fato, um mecanismo de conceptualização humana, de modo a extrapolar a linguagem verbal e o léxico das línguas naturais; por conseguinte, é possível, com o mesmo Forceville (2009), assegurar que os modelos teóricos da SC só atingirão plena validade quando saírem de certa zona de conforto, na qual, unicamente, se explicita, por meio de expressões verbais, o fato de a metáfora e a metonímia interconectarem-se ao pensamento e à ação, extrapolando, por conseguinte, a linguagem. Afinal, como destaca Campos (2008, p. 3), "se puede y debe admitir la posibilidad de que no haya una preeminencia verbal en la construcción metafórica [y metonímica], sino que más bien se trataría de buscar la confluencia de ambos modos como base de la capacidad cognitiva", ${ }^{3}$ como acontece na fala, com verbal, gestual e entonacional, por exemplo.

\section{A TEORIA DA COMPLEXIDADE E SEUS APORTES AO ESTUDO DA CONCEPTUALIZAÇÃO MULTIMODAL ${ }^{4}$}

Opto por traçar um diálogo entre LC e TC porque compreendo a importância de conceber o fenômeno da conceptualização através de uma visão holística e interdisciplinar, dado que o retalhamento disciplinar inviabiliza o entendimento

3 "Pode-se e deve-se admitir a possibilidade de não haver uma proeminência verbal na construção metafórica [e metonímica], mas ao invés se trataria de buscar a confluência de ambos os modos como base da capacidade cognitiva". (Tradução minha.)

4 Preciso destacar que outros pesquisadores, como Paiva (2010), dedicaram-se a pensar sobre a interface Linguística Cognitiva e Teoria da Complexidade. 
do que é tecido junto, ou seja, do complexo, no caso, da conceptualização. Assim, assumo o desafio da globalidade e da existência da complexidade no seio desse fenômeno, pois creio que há complexidade quando elementos formadores de um todo, a exemplo do linguístico, do social, do histórico, não se separam e há um tecido entre as partes e o todo, o todo e as partes, que é interdependente, interativo e inter-retroativo.

O pensar complexo, como explicita Capra (2005), forma interconexões em contraposição às visões reducionistas da ciência. Logo, o pensamento sistêmico concebe o mundo em termos de relações e de integrações. Os sistemas são entendidos como totalidades integradas, e as suas propriedades não devem ser reduzidas a unidades menores, portanto, o olhar sistêmico ressalta os princípios básicos de organização, ao invés de se concentrar nos elementos ou substâncias básicas.

Entendo a conceptualização como um fenômeno complexo e compreendo que, em todo processo de conceptualização, há interconexões entre MCIs metafóricos, metonímicos e esquemoimagéticos e ainda proposicionais, ${ }^{5}$ por conseguinte, considero necessário associar conhecimentos adquiridos pela LC a saberes elaborados pela TC, com a finalidade de estudar a conceptualização multimodal.

Capra e Luisi (2014), ao situarem as três perspectivas da vida, retomam a existência de uma tríade que caracteriza os sistemas vivos - o padrão de organização (forma), a estrutura (matéria) e o processo -, concebendo, com base em Maturana e Varela, o primeiro como "a configuração de relações entre os componentes do sistema, que determina as características essenciais do sistema", o segundo como "a incorporação física do seu padrão de organização" e, finalmente, o terceiro como "a atividade envolvida na incorporação contínua do padrão de organização e estrutura" (CAPRA; LUISI, 2014, p. 373-374).

Compreendo que a linguagem, como parte do ser humano, pode ser, metonimicamente, entendida como um sistema vivo, uma vez que é uma parte constituinte desse mesmo ser humano; entendo que, apenas, uma visão que secciona pedaços de um todo e não os interconecta poderia ver a linguagem independentemente dos seres humanos, inclusive, personificando-a e dando-lhe poder de realizar ações que são, essencialmente, humanas, como se essa fosse independente do humano que a realiza, que a cria, que a recria; ao ver a linguagem como parte da humanidade, concebo-a, a partir da relação metonímica PARTE/TODO que se estrutura, da mesma forma, pelo esquema imagético PARTE/TODO.

5 Aqui, entretanto, não abordarei os Modelos Cognitivos Idealizados Proposicionais. 
Ademais, penso que, no âmbito da conceptualização, os MCIs metafóricos, metonímicos e esquemoimagéticos funcionam como um padrão de organização (forma), enquanto as expressões metafóricas, metonímicas, imagéticas, musicais etc. acham-se no plano da estrutura (matéria). E, finalmente, acredito que há um processo responsável por ligar, continuamente, o padrão de organização (forma) às estruturas (matéria), as quais daquele advêm, ao mesmo tempo em que o criam.

Capra e Luisi (2014) observam que o padrão de organização (forma) caracterizase por ser uma rede autogeradora, logo, autopoética; ${ }^{6}$ creio que os MCIs são padrões de organização porque são redes autogeradoras, enquanto as estruturas materiais, as expressões linguísticas, pictóricas, verbopictóricas e outras, são estruturas dissipativas, são sistemas abertos, operando longe do equilíbrio, sendo a leitura responsável pelo processo, isto é, pelas interconexões entre o padrão de organização (MCIs), que faz parte da cognição humana, e as estruturas (expressões materiais verbopictóricas), que homens, mulheres e crianças produzem, com suas diversas linguagens, em suas diferentes interações.

Como Capra e Luisi (2014, p. 375) ressaltam, "nenhum cientista negaria a existência de padrões e processos, mas a maioria deles tende a conceber um padrão de organização como uma ideia abstraída da matéria, em vez de uma força geradora”. Na LC, de fato, chega-se ao padrão de organização (forma) por meio das expressões verbais, imagéticas, musicais, gestuais, etc., portanto, por meio da estrutura (matéria), mas também se reconhecem as metáforas, as metonímias, os esquemas imagéticos, enfim, os MCIs como uma espécie de matriz criadora de novos padrões de organização. Logo, ocorre uma retroalimentação sistêmica e complexa.

Compreendo, portanto, que os MCIs são recursivos, de modo que participam da conceptualização de experiências, quando o(a) conceptualizador(a) mapeia metonímica e metaforicamente, respectivamente, saberes de um domínio da experiência em outro ou em um mesmo domínio e, ao mesmo tempo, estrutura esses conhecimentos com base em esquemas imagéticos e, simultaneamente, se realimenta com outros conhecimentos elaborados, por meio de nova conceptualização, que, deixando de ser nova, passa a fazer parte do conhecimento adquirido em um dado domínio.

6 Maturana e Varela, na década de 1970, criaram o termo autopoiese, com base em auto 'eu' e poiesis 'fazer a si mesmo' (CAPRA; LUISI, 2014, p. 169). 
Para estender a concepção sistêmica da vida ao domínio social, Capra e Luisi (2014) associam o significado a essas três outras perspectivas (padrão de organização (forma), estrutura (matéria) e processo), de maneira a compreenderem que, no domínio social, opera um quarteto, sendo o significado visto como uma "notação 'taquigráfica' para o mundo interior da consciência reflexiva, o qual contém uma multidão de características inter-relacionadas" (CAPRA; LUISI, 2014, p. 377). Ora, a linguagem, para além de ser um fenômeno biológico, é um fenômeno social, que, na humanidade, vive, em autopoiese, na constituição do significado, nos pensamentos e nas ações da espécie.

A LC assume, por conseguinte, o desafio da complexidade, afinando-se com as perspectivas da TC que, por sua parte, podem contribuir com a migração de algumas concepções, para que os linguistas cognitivistas possam entender melhor a linguagem em sua multimodalidade. A linguagem não é constituída, apenas, pela propriedade da matéria, mas por um padrão de organização entre processos ântropo-bio-psico-geo-sócio-histórico-culturais, além é claro de processos fônico-mórfico-sintático-semântico-pragmático-discursivos, além de processos envolvendo sistemas de cores, de sons, de gestos, de cheiros, de contatos, etc.; tudo isto em relação, pois, sem interconexão não há linguagem, não há significado, logo, não há ação, nem mesmo a própria humanidade.

Quando os componentes que constituem um todo (como o pictórico, o verbal, o(a) conceptualizador(a) - produtor(a)/leitor(a), pesquisador(a)/leitor(a), leitor(es) potencial(is) -, os mecanismos de conceptualização - metáforas, metonímias, esquemas imagéticos -, os contextos geo-sócio-político-históricos) são inseparáveis e existe um tecido interdependente, interativo e inter-retroativo entre as partes e o todo, e entre o todo e as partes, existe complexidade, o que concluo, com base no pensamento moriniano (MORIN, 2009).

Penso que só existe sentido no processo de interação em conexão entre o(a) criador(a) do meme, um(a) conceptualizador(a), as diferentes linguagens por ele(a) utilizadas (cores, tipos e tamanhos de letras, logo escrita, diagramação, design... etc.) e um(a) potencial leitor(a), no caso específico, o(a) pesquisador(a), também, um(a) conceptualizador(a) dos sentidos elaborados por meio do meme estudado. $\mathrm{Na}$ relação criador(a)/conceptualizador(a)-memes-elementos constituintescontexto-leitor(a)/pesquisador(a)/conceptualizador(a), ocorre a elaboração dos sentidos, vistos como um sistema dinâmico, aberto, auto-organizado. 
Trago Morin (2009), mais uma vez, porque ele sintetiza a premência da complexidade e de um pensamento sistêmico que compreenda ser o conhecimento das partes dependente do conhecimento do todo e que entenda ser o conhecimento do todo dependente do conhecimento das partes; que reconheça e estude os fenômenos multidimensionais, em vez de isolar, de maneira mutiladora, cada uma de suas dimensões; que reconheça e trate as realidades, que são, concomitantemente, solidárias e conflituosas, que respeite a diferença, enquanto reconhece a unicidade.

Assumo que "o princípio sistêmico ou organizacional, que liga o conhecimento das partes ao conhecimento do todo" (MORIN, 2009, p. 93) é válido, para se saber, por exemplo, que um dado meme é constituído por uma dada cor, um dado tipo de letra, ou por certa expressão metafórica ou metonímica, mas um meme tão somente será um meme, quero dizer, apenas fará sentido a(o) seu(ua) potencial leitor(a) se o conhecimento das suas partes for interconectado ao conhecimento do seu todo, pois, como observa o mesmo Morin (2009), a organização do todo gera novas qualidades ou propriedades, que são as chamadas emergências. Assim, o todo é maior do que a soma das suas partes e, também, menor, uma vez que algumas qualidades são inibidas pela geração do conjunto.

Penso, enfim, que a adoção da TC favorecerá uma compreensão mais aprofundada, a respeito da forma como os diferentes mecanismos de significação se relacionam entre si e também com o social, autoinfluenciando-se, fazendo emergir e gerando significados. A complexidade bem como a dinamicidade atrelam-se tanto à inter-relação entre os diferentes modos semióticos, quanto ligam-se à inter-relação entre distintos sistemas envolvidos no processo de elaboração do significado, como o social, o linguístico, o cultural, o social, o econômico, etc., gerando, entre conceptualizadores em interação, os diferentes sentidos.

\section{PERCURSO PARA A COMPREENSÃO DO CORPUS}

Relativamente ao desenho metodológico do estudo desenvolvido, foi utilizada uma abordagem qualitativa, de natureza bibliográfica, documental, exploratória, além de descritiva, ao mesmo tempo interpretativa. Foi realizado o estudo do conteúdo, considerando o viés da hermenêutica. Esses caminhos foram seguidos, porque, nem o ser, nem a existência, nem o sujeito devem ser expressos, matematicamente ou por meio de fórmulas (MORIN, 2009). E é exatamente o modo de o ser humano compreender outros seres humanos, as instituições criadas 
por eles próprios, logo, a experiência que constitui o nó górdio do estudo que foi desenvolvido.

Entre os avanços introduzidos pela LC no tratamento da conceptualização, pontuo seu interesse por refletir sobre o uso ubíquo da metáfora e, também, da metonímia no cotidiano; de fato, estudos cognitivistas mostram, sem dificuldades, que usos ditos "figurativos da linguagem" não estariam limitados ao meio literário, pelo contrário, o espaço comum de manifestação desses usos seria a linguagem do dia a dia, uma vez que essa reflete, sendo a ponta do iceberg, a forma habitual de o ser humano pensar. Assim, constituí o corpus utilizando-me de uma ferramenta de comunicação contemporânea, como já explicitado, o Facebook, além ter direcionado as discussões para as manifestações de conceptualização, como também informado, no gênero meme, postado na página Movimento Contra Corrupção, $\mathrm{MCC},{ }^{7}$ dado que esse é amplamente empregado nesse tipo de rede social e, acima de tudo, focalizei discussões sobre uma questão ântropo-geosócio-política atual: o embate por poder que cria realidades, isto para buscar entender como alguns brasileiros compreendem a questão, particularmente, a conceptualização da presidenta Dilma Rousseff, do PT, seu partido, dos seus eleitores e do seu governo, como indicado antes.

\section{UM EXERCÍCIO DE COMPREENSÃO: O ESTUDO DAS CONCEPTUALIZAÇÕES}

Feitas as observações atinentes ao percurso metodológico, será, na sequência, apresentado o estudo do meme selecionado. Neste, a presidenta Dilma Rousseff foi conceptualizada como um medicamento, tendo sido a conceptualização feita por meio da metáfora criativa Presidente/Dilma Rousseff é MEdiCAMENTo:

7 Segundo informações constantes desta página, sua criação se deu em 2010, e, entre seus objetivos, acha-se a divulgação de notícias de casos de corrupção, de modo a gerar informes para a população, além da promoção de estudos atinentes à corrupção. Assim, compreendo que a mesma pode ser estudada e os resultados ora expostos seguem um dos objetivos propostos por seus criadores. $\mathrm{O}$ endereço eletrônico da página é: $<$ https://www.facebook.com/MovimentoContraCorrupcao? $\mathrm{fref}=\mathrm{ts}>$. Acesso em 5 out. 2015. 




FIGURA 1 - Meme Novadilma.

Fonte: Disponível em: $<$ https://www.facebook.com/MovimentoContraCorrupcao/ photos/a.257980104314265.49913. 254329351346007/691047434340861/?type=1\&theat er>. Acesso em: 1. ago. 2015.

O domínio-fonte, medicamentos, foi instanciado tanto através da linguagem pictórica, com a apresentação da imagem da caixa da medicação contendo drágeas do remédio, quanto por meio da linguagem verbal, com o uso de algumas unidades linguísticas. Já o domínio-alvo, presidenta Dilma Rousseff, foi acessado por meio da linguagem verbal, particularmente por meio do item lexical criativo onomástico Novadilma.

Além de metafórica, essa conceptualização é metonímica, já que, no tocante aos conhecimentos enciclopédicos do domínio-fonte, quando se acessam saberes sobre medicamentos, geralmente, retomam-se benefícios que esses podem trazer para aqueles que os utilizam. No entanto, no caso em tela, foi recobrada a contraparte negativa dos remédios, de modo que, na caixa desse medicamento, quando se expõe a sua composição, foram destacados, por meio de um léxico inovador, pontos negativos que alguns atribuem ao governo da presidenta, como o aumento do combustível, um suposto esquecimento de promessas de campanha, uma governança frágil, o que é um processo metonímico ativado, nessa conceptualização, do tipo PARTE PELO TODO, dado que apenas são postos em foco aspectos considerados negativos do governo Rousseff, silenciando-se, por exemplo, todos avanços atrelados aos benefícios sociais alcançados; assim sendo, essa conceptualização metonímica acha-se estruturada pelo esquema imagético PARTE/TODO e foi acionada pela interação de elementos verbais e imagéticos constituintes do meme. 
O Novadilma é indicado apenas para os eleitores de Rousseff, ou seja, para $53 \%$ da população que, agora, não reconheceria ou não se recordaria em quem votou, logo, o remédio seria para quem não assumiria ter votado nela; neste caso, ocorre, então, a conceptualização dos seus votantes por meio da metáfora criativa eleitor da Presidenta é doente, da qual o domínio-fonte, o das doenças do esquecimento, foi acessado quer por meio da linguagem verbal ("Indicado para 53\% da população que não admite (ou lembra) em quem votou”), quer pela imagética (drágeas, etc.), em interconexão, nesse meme; já o domínio-alvo, eleitor da presidenta, foi acionado pelo modo verbal, exclusivamente.

O partido dos trabalhadores, por sua vez, foi conceptualizado por meio da metáfora criativa PT É FABRICANTE DE MEDICAMENTos, cujo domínio-alvo, PT, foi acessado pela linguagem imagética, já que, no centro da caixa do Novadilma, foi inserida a imagem de uma estrela no centro de um círculo, em que se usaram as cores vermelha e branca e, ainda, pela exposição de drágeas vermelhas do medicamento, possibilitando acessar, por meio da metonímia SíMBOLO POR PT/PARTE PELO TODO, o domínio-alvo envolvido na conceptualização, a qual é estruturada pelo esquema imagético PARTE/TODO e acionada pela linguagem imagética. Já o domínio-fonte, fabricante de medicamento, foi acessado pela interação da linguagem verbal ("Indicado para $53 \%$ da população que não admite (ou lembra) em quem votou", etc.) com a imagética (caixa de medicamento, drágeas). Ademais, há o esquema RECIPIENTE, estruturando o mapeamento metafórico; há, nesse caso, a compreensão atinente à ingestão pelo ser humano (um recipiente) do medicamento, o que se associa à metáfora PRESIDENTA É MEDICAMENTO.

$\mathrm{O}$ atual mandato da presidenta foi conceptualizado por meio da metáfora NOVO GOVERNO É VELHO GOVERNO, que aparece materializada por uma expressão linguística metafórica localizada na margem direita superior da caixa do medicamento, em um balão azul ("novo governo para velhos problemas"). Os dois domínios são recuperados, nessa conceptualização, por meio da linguagem verbal. Foi compreendido que novo seria o tempo do governo, mas os problemas, as suas supostas doenças, seriam as mesmas, portanto, o governo seria velho com suas supostas mazelas.

Trazendo para a discussão a TC, compreendo que a estrutura (matéria) possibilita o acesso ao padrão de organização (forma), os quais se interconectam no meme por meio do processo de elaboração do significado realizado por um(a) potencial leitor(a), assim como, por meio desse padrão de organização, pôde ser gerado esse meme e poderão ser criados outros. 
Do ponto de vista do padrão de organização (forma), há, interligados, nesse meme, metáforas conceptuais (Presidente/Dilma Rousseff é medicamento, eleitor da Presidenta É doente, PT É fabricante de medicamentos e novo GOVERno É VELHO GOVERNo), metonímias conceptuais (Símbolo PELO PT/PARTE PELO TODO) e esquemas imagéticos (PARTE/TODO e RECIPIENTE).

Ainda no tocante às estruturas, chamou a minha atenção a criação de um vocabulário inovador: aumentolato de gasolenídeo, esquecilado de campanhalol, parecequetamal, além do onomato Novadilma e, da mesma forma, a inserção da cor que, metonimicamente, categoriza o PT, quero dizer, o uso do vermelho. Padrão e estrutura são unidos pelo(a) leitor(a), que realiza, em suas leituras, as suas (re)conceptualizações, ratificando ou não suas ideologias.

Ainda sobre esse léxico inovador, matéria que expressa o padrão de organização conceptual em interconexão por processo, apesar de inovador, a elaboração desse léxico só foi possível porque o(a) conceptualizador(a)/criador(a) do meme conhece as construções do português, de modo a unir, simbioticamente, grafia-fonologiamorfologia-léxico-sintaxe-semântica-pragmática-discurso sem que haja qualquer hierarquia entre esses sistemas; além disso, a sua validade só foi possível, por ocorrer interação desses sistemas por meio de uma rede ântropo-bio-psico-geosócio-histórico-cultural que faz com que o sentido possa ser elaborado pelos seus leitores.

Com base em contribuições da TC, devo observar, assim, que não se trata da soma das partes para chegar a um todo, por exemplo, não se trata da soma caixa da imagem do medicamento Novalgina $+\ldots+$ léxico + sintaxe + semântica $+\ldots+$ cores $\ldots+\ldots$ linhas $\ldots+\ldots$ tipos de letras $+\ldots$ etc., já que ocorre um deslocamento conceptual que, por sua parte, gera uma (re)conceptualização do medicamento, que passa a ser concebido de modo bem distinto; assim sendo, o todo é mais e, ao mesmo tempo, é menos do que a soma de suas partes.

Se eu considerar a caixa do Novalgina, eu vejo ordem, tudo está organizado para que o seu consumidor use esse medicamento, quando prescrito por seu médico, porém, para a criação do meme Novadilma, foi necessário que ocorresse um deslocamento, de tal modo que esse deslocamento das imagens da caixa do medicamento Novalgina para criar o Novadilma gera uma espécie de desordem e dessa será criada uma nova organização, uma vez que novos sentidos poderão ser elaborados pelos seus leitores potenciais: 


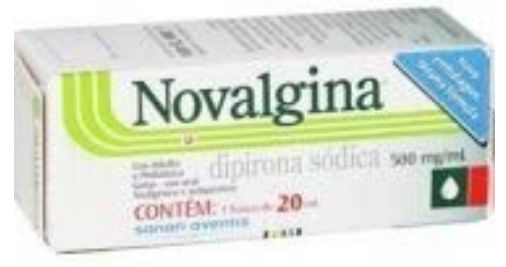

FIGURA 2 - Caixa do medicamento Novalgina.

Fonte: Disponível em: https://images.consultaremedios.com.br/186x186/7891058489038

Ocorre, então, desequilíbrio entre ordem e desordem, para gerar organização; no meme, a ordem está na manutenção dos elementos básicos sígnicos da caixa do medicamento, como as cores verde e branco, a disposição das informações, etc., mas a desordem é instaurada quando, por exemplo, é substituída parte da logo do medicamento, um círculo vermelho e branco, por um círculo contendo a estrela do PT, ou quando é feito o uso da cor vermelha nas drágeas, em vez do branco do comprimido original; é dessa desordem que se cria uma nova organização, no âmbito da dialógica ordem/desordem/organização, lembrando que é a organização gerada no encontro da ordem e da desordem.

Acontece, assim, um deslocamento da categorização do medicamento, que passa a ser (re)conceptualizado, de modo a possibilitar a formação de novos sentidos, tanto para aqueles leitores que compartilham dessa reconceptualização, quanto outros que a rechaçaram, pois conceptualizam a presidenta, o seu partido, o seu governo e, principalmente, a si próprios, de outro modo, sendo suas respectivas conceptualizações, inclusive, opostas àquela conceptualização do meme. Do ponto de vista da ecologia social brasileira, essas (re)conceptualizações refletem a polaridade do país nas urnas de 2014, que levaram às atuais divergências políticas que têm dividido o país entre "petralhas"/“mortadelas" e "coxinhas", o que vem ocultar os reais e sistêmicos problemas de corrupção que, em seu âmago, o Brasil enfrenta.

Considerando, ainda, o postulado por Bauman (2007), devo destacar toda a fluidez dessas postagens do Facebook que se evaporam, inclusive, levando consigo as construções verboimagéticas criadas. Apesar disso, esse tipo de meme, circulando nas redes sociais, como o Facebook, pode gerar discussões, no seio da sociedade brasileira, porque expressa ideologias dos seus criadores, reproduzindoas e propagando-as e, ao mesmo tempo, indo ao encontro de outras ideologias que se acham no mundo da noosfera (MORIN, 2011). 


\title{
PARA CONCLUIR
}

Os padrões de organização (forma), de um lado, são responsáveis por criar, por meio do fenômeno da conceptualização, expressões verbais e imagéticas, estruturas (matéria) que se interconectam pelo processo de leitura tanto na constituição dos memes quanto em sua recepção e, de outro lado, a partir dessas expressões, é possível chegar aos padrões de organização de conceptualização. Por sua vez, esses memes propagam-se, viralmente, na internet, e fazem parte da constituição de uma rede de comunicação, criando ideias concebidas, muitas vezes, como verdades absolutas, gerando novos imprintings e normalizações de ideias, e, assim, passam a fazer parte da noosfera, criando, inclusive, novas realidades (MORIN, 2011), e, inclusive, forjando situações falaciosas. Realizado o estudo, verifiquei o papel da interconexão entre imagético e verbal, na conceptualização, e identifiquei a construção de sentidos, por meio de mapeamentos metafóricos e metonímicos, estruturados por esquemas imagéticos, bem como constatei que, na multimodalidade, o todo é mais e menos do que a soma de suas partes (MORIN, 2009).

\section{Brazil, 2015: how the president, her party, her electors and her government can be conceptualized in social network}

\begin{abstract}
Results are presented from a study on how President Dilma Roussef, her party, her voters, and her government were conceptualized in a meme posted on page Movimento Contra Corrupção constantly part of social network Facebook. The study was guided by theoretical and methodological contributions of Cognitive Linguistics. As conceptualization is a complex phenomenon, knowledge acquired by Cognitive Linguistics were combined with the knowledge developed by Complexity Theory. Reflections were developed on metaphorical and metonymic mappings, structured by imagistic schemes under the scope of this conceptualization. At the end of the work, it was confirmed the role of interconnection between the imagetic and the verbal to create meaning, and it was observed that, in multimodality, the whole is more than the sum of its parts, as well as the whole is less than the sum of its parts.
\end{abstract}

Keywords: Conceptualization. Cognitive Linguistics. Complexity Theory. Multimodality. Meme. 


\section{Referências}

BAUMAN, Zygmunt. Tempos líquidos. Tradução de Carlos Alberto Medeiros. Rio de Janeiro: Zahar, 2007.

BENEVENUTO, Fabrício; ALMEIDA, Jussara M.; SILVA, Altigran S. Explorando redes sociais on-line: da coleta e análise de grandes bases de dados às aplicações. Porto Alegre: Sociedade Brasileira de Computação, 2011.

CAMPOS, Carmen. "La cara es el alma del cuerpo". Metáfora y pensamiento visual, 2008. Disponível em: <http://www.ae-ic.org/santiago2008/contents/pdf/ comunicaciones/281.pdf>. Acesso em: 3 fev. 2016.

CAPRA, Fritjof. As conexões ocultas: ciência para uma vida sustentável. Tradução de Marcelo Brandão Cipolla. São Paulo: Cultrix, 2005. Original publicado em 2002.

CAPRA, Fritjof; LUISI, Pier Luigi. A visão sistêmica da vida: uma concepção unificada e suas implicações filosóficas, políticas, sociais e econômicas. Tradução de Mayra Teruya Eichemberg e Newton Roberval Eichemberg. São Paulo: Cultrix, 2014.

CASTELLS, Manuel. Redes de indignação e esperança: movimentos sociais na era da internet. Tradução de Carlos Alberto Medeiros. Rio de Janeiro: Jorge Zahar, 2013.

COIMBRA, Rosa Lídia. Quando a garrafa é um porco: metáforas (verbo)pictóricas no texto publicitário. In: ENCONTRO NACIONAL DA ASSOCIAÇÃO PORTUGUESA DE LINGÜÍSTICA, 15., 2000, Braga. Actas... Braga: APL, 2000. v. 1, p. 243-253. Disponível em: $<$ http://sweet.ua.pt/rlcoimbra/documentos/ rlcoimbra_15APL_2000.pdf $>$. Acesso em: 22 abr. 2008.

FAUCONNIER, Gilles. Mental spaces. Cambridge: Cambridge University Press, 1994.

FORCEVILLE, Charles. Pictorial metaphor in advertising. London/New York: Routledge, 1996.

FORCEVILLE, Charles. Multimodal metaphor in ten dutch TV commercials. Public Journal of Semiotics, v.1, n. 1, p. 15-34, Jan. 2007.

FORCEVILLE, Charles. Non-verbal and multimodal metaphor in a cognitivist framework: agendas for research. In: FORCEVILLE, Charles; URION-APARISI, Eduardo. Applications of cognitive linguistics: multimodal metaphor. New York: Mouton de Gruyter, 2009. 
KRESS, Gunther. Multimodality. A social semiotic approach to contemporary communication. New York, Routledge, 2013.

KRESS, Gunther; VAN LEEUWEN, Theo. Reading images: the grammar of visual design. London: Routledge, 2006.

MATURANA, Humberto R.; VARELA, Francisco J. A árvore do conhecimento: as bases biológicas da compreensão humana. Tradução de Humberto Mariotti e Lia Diskin. São Paulo: Palas Athena, 2001. Original publicado em 1984.

MORIN, Edgar. A cabeça bem-feita: repensar a reforma, reformar o pensamento. Tradução de Eloá Jacobina. Rio de Janeiro: Bertrand, 2009. Original publicado em 1999.

MORIN, Edgar. O método 4: as ideias: habitat, vida, costumes, organização. Tradução de Juremir Machado da Silva. 5. ed. Porto Alegre: Sulina, 2011. Original publicado em 1991.

PAIVA, Vera Lúcia Menezes de Oliveira e. A metonímia como processo fractal multimodal. 2010. Disponível em: $<$ http://www.ufjf.br/revistaveredas/ files/2010/08/ ARTIGO-1.pdf>. Acesso em: 4 fev. 2016.

RADDEN, Günter; KÖVECSES, Zoltán. Towards a theory of metonymy. 2007. Disponível em: $<$ http://www.ccla2006.com/news.asp?newsid=216>. Acesso em: 10 set. 2015.

RUIZ, Javier Herrero. The role of metaphor, metonymy and conceptual blending in understanding advertisements: the case of drug-prevention ads. Revista Alicantina de Estudios Ingleses. v. 19, p. 169-190, 2006.

SCHRÖDER, Ulrike. A Metáfora Corporificada e sua Função Multimodal para o Jogo de Linguagem 'Duelo Verbal' no Hip Hop. 2013. Disponível em: <www.eba. ufmg.br/revistapos/index.php/pos/article/download/115/90>. Acesso em: 20 mar. 2016 .

Recebido em 31/03/2016.

Aceito em 05/07/2016. 